\title{
Violence against health care staff by patient's visitor in general hospital in Greece: Possible causes and economic crisis
}

\author{
Evmorfia Koukia*, Polyxeni Mangoulia, Nikolaos Gonis, Theofanis Katostaras \\ Faculty of Nursing, University of Athens, Greece \\ Email: ${ }^{*}$ ekoukia@nurs.uoa.gr
}

Received 1 October 2013; revised 25 October 2013; accepted 2 November 2013

Copyright (C) 2013 Evmorfia Koukia et al. This is an open access article distributed under the Creative Commons Attribution License, which permits unrestricted use, distribution, and reproduction in any medium, provided the original work is properly cited.

\begin{abstract}
This study examined the types of violence experienced by physicians, nurses and nurse assistants in various departments by patients' visitors. Few studies have focused on patients' visitors' violence against nurses or physicians in general hospitals and various departments in the beginning of economic crisis in Greece. A total of 250 health care staff-physicians, nurses, nurses' assistants- took part in a questionnaire-based study. A majority of respondents had experienced some forms of violence (verbal, psychological, physical and sexual). The most frequently reported incident was verbal violence followed by psychological violence. Violation of visiting hours and long waiting periods were among the most common causes of violence. Associations were found between workplace violence and demographics and types of wards. Nurses identified economic crisis to be the major cause of violence. The most significant finding is the high rate of workplace violence caused by patients' visitors due to economic crisis and the fact that we found no statistically significant differences in the prevalence of violence among different health professionals.
\end{abstract}

Keywords: Workplace Violence; Health Care Professionals; Visitor

\section{INTRODUCTION}

Health care staff are the most risky professionals to violence in the workplace [1]. In recent years researchers had focused on workplace violence directed especially at nurses [2-6]. Most studies have examined violence against nurses by patients especially in psychiatric and

\footnotetext{
"Corresponding author.
}

emergency settings [7-9].

Few studies have systematically explored violence against nurses and physicians by patients' visitors in general settings [10,11]. Most of the studies had emphasized on patient violent acts against health care staff [12-16].

A review of the literature illustrates that aggressive and violent behavior is caused mainly by patients and visitors [15,17-20]. Previous studies have shown that incidents of violence are experienced by nurses influence job satisfaction, job performance and quality of patients' care; moreover it causes psychological harm to victims [21-25]. In addition, a number of studies had illustrated the psychological and emotional impact of violence especially on nurses [26,27].

Greece, since June 2011, has been facing a major economic crisis due to large debt and begins to implement austerity measures. Since then a few studies mainly focusing on mental health issues, have tried to identify the impact of this crisis. To our knowledge, there is no study, which examines the effect of economic crisis in the frequency of violent episodes' incidence in Greek hospitals.

Additionally in Greek health care system, staff shortage impedes the continuing presence of patient's visitors - usually a family member-in all nursing and medical procedures. In many cases, performing these procedures depends on aid provided by the patient's relatives. Patient care depends on relatives and as a result relatives may become anxious, angry and frustrated, which as a consequence could possibly lead to violent acts towards staff.

\section{AIM OF THIS STUDYS}

The aims of the study were to:

1) Examine the types of violence experienced by physicians and nurses in various departments by patients' visitors;

2) Identify the possible causes; 
3) Determine the association of economic crisis and violent episodes.

\section{MATERIALS AND METHODS}

\subsection{Study Design}

The study was conducted in seven general hospitals in Athens, Greece, greater area. The hospitals provide services for patients from rural, semi-urban and urban backgrounds as well as for patients from ethnic minorities.

Ethical approval to conduct this research study was obtained from the hospital ethics committees. Questionnaires were returned confidentially directly to one of the authors. Assurances were given to nurses and physicians on duty concerning confidentiality and anonymity. Participation in the research was contingent on individual verbal consent.

An anonymous self-administered questionnaire was constructed by the Demographic Laboratory in The Faculty of Nursing, University of Athens. A modified version of this instrument has already been used in another study conducted by the same scientific group concerning violence amongst health care staff. The questionnaire pre-tested ten nurse and five doctors who were not included in the final study. Content validity was examined by two experts, one associate professor on Health Economics and one assistant professor in psychiatric nursing. Content validity index was 0.91 . Cronbach alpha coefficient was 0.79 . The data were collected between October and December 2011.

\subsection{Instrument}

In the first part of the questionnaire we included:

- The participants' demographic characteristics and

- Information about definition of violence (verbal, psychological, physical and sexual violence).

The second part comprised three parts including:

1) Types of violence-psychological, verbal, physical, sexual-according to different shifts (morning-eveningnight shift).

The respondents were requested to answer whether he or she had experienced violence ("yes" or "no") during their career in the same department by a visitor.

2) Perceived causes of violence.

3) An empty box at the end of the pages in order for the health care staff to feedback with any additional information and provide an answer to the following question: "Have you noticed an increase in the frequency of the violent episodes since the onset of the economic crisis?"

\subsection{Data Collection}

The researcher informed the head nurse and the head doctor of each ward on the purpose of the study and the nurse in charge informed the nursing staff. Questionnaires were distributed to all nurses and physicians over 3 months period.

Written approval was obtained by the hospitals' ethical committees. Participation in the research was contingent on individual verbal consent. Assurances were given to nurses on duty, concerning confidentiality and anonymity.

The sample consisted of 320 health care staff, medical specialists, resident doctors, registered nurses, assistant nurses who worked full-time - three rotating shifts - in seven types of wards in seven general hospitals. The final sample was 250 health care staff. The staff was randomly selected from morning and evening shift all health care staff was in regular contact with patients.

\subsection{Data Analysis}

We used a descriptive analysis to identify violence characteristics. A logistic regression analysis was used in order to identify factors that may predict a certain type of violence. The following independent variables (victims' characteristics) were chosen: gender, age, height and weight, marital status, years of work and hospital department. Data was analyzed by Statistical Package for Social Sciences (SPSS, version 13). Content analysis was applied on health care staff comments and the data was coded in order to identify a variety of themes.

\section{RESULTS}

\subsection{Respondents' Characteristics}

Questionnaires were distributed to 320 health care staff, 250 of who responded. This represents a $78 \%$ response rate. The mean age of the respondents was 36.3 ( $\mathrm{SD}=$ 5.2). Sixty six (26.4\%) were male and 184 (73.6\%) were female. The mean years of work in a generals' hospital setting were $11.7 \pm 5.2$ years. Thirty six $(14.4 \%)$ were medical specialists, $54(21.6 \%)$ were resident doctors, $132(52.8 \%)$ were registered as nurses and $28(11.2 \%)$ were nurse assistants. The demographic characteristics of the sample are presented in Table 1.

\subsection{Prevalence of Violence}

Two hundred two $(80.8 \%)$ health care staff experienced verbal violence by visitor in the morning shift, 192 $(76.8 \%)$ in the evening shift, $114(45.6 \%)$ in the night shift, followed by psychological violence 192 (76.8\%), $184(73.6 \%)$ and $102(40.8 \%)$ respectively.

The results showed violent events were not time-dependent (Table 2).

\subsection{Perceived Causes of Violence}

Nurses and doctors identified nine (9) perceived causes 
of violence by visitors. The most frequent causes of violent acts by the visitor were: violation of visiting hours (88.8\%), long waiting periods $(86.4 \%)$, psychological problems like anger and anxiety $(83.2 \%)$ and smoking prohibition (82.4\%) (Table 3).

Table 1. Demographic characteristics $(\mathrm{N}=250)$.

\begin{tabular}{lcc}
\hline \multicolumn{2}{c}{ Characteristics } & N (\%) \\
\hline Males & \multicolumn{1}{c}{ Sex } & $66(26.4)$ \\
Females & Age & $184(73.6)$ \\
& \multicolumn{1}{c}{ Years of work } & $\mathrm{X}=36.3 \pm 5.2$ \\
\multicolumn{1}{c}{$\quad$ Position } & $\mathrm{X}=11.7 \pm 5.2$ \\
Medical specialist & \\
Resident doctor & $36(14.4)$ \\
Registered nurse & $54(21.6)$ \\
Nurse assistant & $132(52.8)$ \\
\multicolumn{1}{c}{ Type of ward } & $28(11.2)$ \\
Internal medicine & \\
Surgical & $62(24.8)$ \\
Anesthesiology & $44(17.6)$ \\
Cardiology & $12(4.8)$ \\
Emergency & $28(11.2)$ \\
ICU & $30(12.0)$ \\
Orthopedics & $54(21.6)$ \\
\hline
\end{tabular}

Table 2. Prevalence of violence by visitor according to different shifts $(\mathrm{N}=250)$.

\begin{tabular}{cccc}
\hline Violence type & $\mathbf{7 - 3}$ & $\mathbf{3 - 1 1}$ & $\mathbf{1 1 - 7}$ \\
& $\mathbf{N ~ ( \% )}$ & $\mathbf{N}(\mathbf{\%})$ & $\mathbf{N}(\%)$ \\
\hline Psychological & $192(76.8)$ & $184(73.6)$ & $102(40.8)$ \\
Verbal & $202(80.8)$ & $192(76.8)$ & $114(45.6)$ \\
Use of force & $64(25.6)$ & $70(28.0)$ & $54(21.6)$ \\
Physical & $70(28.0)$ & $60(24.0)$ & $54(21.6)$ \\
Sexual & $64(25.6)$ & $62(24.8)$ & $34(13.6)$ \\
\hline
\end{tabular}

Table 3. Perceived causes of violence.

\begin{tabular}{cc}
\hline Perceived causes of violence & N (\%) \\
\hline Violation of visiting hours & $222(88.8)$ \\
Long waiting periods & $216(86.4)$ \\
Psychological problems (anger, anxiety) & $208(83.2)$ \\
Smoking prohibition & $206(82.4)$ \\
Denial of patient's admission in the hospital & $168(67.2)$ \\
Delays in nursing care provision & $164(65.6)$ \\
Delays in medical care provision & $150(60.0)$ \\
Denial of patient's dismiss ion & $122(48.8)$ \\
Patients' dissatisfaction with nursing/medical care & $80(32.0)$ \\
\hline
\end{tabular}

\subsection{Logistic Regression Analysis (Table 4)}

Logistic regression analysis showed that in cases where the visitor was the perpetrator, health care staff in younger age had increased odds of experiencing psychological violence $(\mathrm{p}<0.003)$.

Victims with lower height had also increased odds of experiencing physical $(\mathrm{p}<0.000)$ and sexual violence $(\mathrm{p}$ $<0.000)$ respectively.

Years of work were found to predict verbal violence. Those with fewer years of work had a greater risk of experiencing verbal violence $(\mathrm{p}<0.017)$.

Working in Internal medicine increased the risk of experiencing psychological $(p<0.000)$, verbal $(p<$ $0.000)$, physical $(\mathrm{p}<0.000)$ and sexual violence $(\mathrm{p}<$ $0.013)$.

Working in surgical and anesthesiology increased the risk of psychological violence $(p<0.000, p<0.000)$ and verbal violence $(p<0.000, p<0.000)$ respectively.

Those who worked in emergency had increased odds of experiencing sexual violence $(\mathrm{p}<0.033)$.

\subsection{Content Analysis of Open-Ended Question}

The total of sample answered "yes" to the question concerning the impact of economic crisis. They all agreed that during the last months they have noticed an increase in violent episodes' incidence.

One hundred fifty $(60 \%)$ nurses and physicians has chosen to make a comment concerning violent incidents. The main issues raised from nurses and physicians' quotes were:

1) Economic crisis has been identified as the major cause of an increase in the frequency of violent incidents, in public hospitals. Both health care staff and visitors are more stressed and have lowered ability to manage a crisis.

Health care staff admitted that in many cases they have no courage to confront an angry and frustrated patient and his/her visitor. On the other hand the visitor is more demanding, in fear that the patient will not receive the adequate care. Staff shortage, reduction on salary and lack of medical supplies were some of the causes mentioned by the staff.

2) No training in violence de-escalation strategies and prevention management. Health care staff reported that they lack the knowledge and the skills to handle with violent visitors. More training would make them more confident and equipped to deal with this particularly stressed group.

3) Personnel shortage-Effect on quality of patient care. Lack of staff combined with lack of time impairs quality of patient care and communication with patient relatives. In addition patient care in Greek hospital system depends on relatives presence in the hospital 
Table 4. Logistic regression analysis results: patient's visitor as the perpetrator.

\begin{tabular}{|c|c|c|c|c|c|c|}
\hline \multirow{2}{*}{$\begin{array}{l}\text { Independent } \\
\text { variable }\end{array}$} & \multirow{2}{*}{ B } & \multirow{2}{*}{ Odds Ratios } & \multicolumn{2}{|c|}{ 95\% C.I for OR } & \multirow{2}{*}{$\mathrm{p}$ value } & \multirow{2}{*}{$\begin{array}{l}\text { Dependent } \\
\text { variable }\end{array}$} \\
\hline & & & Lower & Upper & & \\
\hline Age & -0.100 & 0.905 & 0.848 & 0.966 & 0.003 & Psychological violence \\
\hline Internal medicine & 1.770 & 5.872 & 2.833 & 12.169 & 0.000 & Psychological violence \\
\hline Surgical & -1.957 & 0.141 & 0.067 & 0.298 & 0.000 & Psychological violence \\
\hline Anesthesiology & -2.525 & 0.080 & 0.022 & 0.291 & 0.000 & Psychological violence \\
\hline Years of work & -0.073 & 0.930 & 0.876 & 0.987 & 0.017 & Verbal violence \\
\hline Internal medicine & 1.727 & 5.623 & 2.766 & 11.432 & 0.000 & Verbal violence \\
\hline Surgical & -1.549 & 0.224 & 0.105 & 0.478 & 0.000 & Verbal violence \\
\hline Anesthesiology & -1.731 & 0.026 & 0.005 & 0.124 & 0.000 & Verbal violence \\
\hline Height & -0.088 & 0.916 & 0.877 & 0.956 & 0.000 & Physical violence \\
\hline Years of work & -0.139 & 0.870 & 0.817 & 0.926 & 0.000 & Physical violence \\
\hline Internal medicine & 1.162 & 5.119 & 2.534 & 10.342 & 0.000 & Physical violence \\
\hline Height & -0.159 & 0.853 & 0.791 & 0.920 & 0.000 & Sexual violence \\
\hline Internal medicine & 1.147 & 3.148 & 1.698 & 5.838 & 0.013 & Sexual violence \\
\hline Emergency & -1.791 & 0.167 & 0.032 & 0.864 & 0.033 & Sexual violence \\
\hline
\end{tabular}

especially in the night shift. This interaction may cause tension and misunderstandings for both parts. Nurses especially accused relatives of wasting staff time by unreasonable demands.

4) Low reporting of violence and management inadequacy to handle incidents. Most of the respondentsespecially nurses - noted that nursing or medical administration would never come to their aid even if they had reported the incident. In addition lack of policies and security rules maximizes consequences of workplace violence.

\section{DISCUSSION}

This study tried to separate the types of violence (verbal, psychological, physical, sexual) caused by patient's visitors and to determine the risk factors associated with workplace violence. In Greek health care system, visitors are mainly patient relatives. To interpret the results, it has to be noticed that in Greek health care system patient's relative play a key role in patient care. Patients' relative monitors symptoms and signs, participates in the patient's self care, stays near the patient overnight and sometimes performs nursing practices. This phenomenon is a direct consequence of a significant lack in health care staff. The effective delivery of care in most of the cases is based on relatives.

The most significant finding is the high rate of workplace violence caused by patients' visitors due to economic crisis in Greece. The overwhelming majority of nurses and physicians participating in this research reported facing all types of violent behavior in the workplace. The results also show that physicians and nurses, almost equally, are at a serious risk in the general health care environment, even though a previous study has shown that nurses were more likely to experience violent incidents than physicians $[11,16]$.

A possible explanation could be that in Greece, lack of policies and assertive legislation, has placed health care staff at frequent risk for workplace violence [28]. In addition to that, another reason may be that in Greece the shortage of health care staff is combined with a large workload. The fact that visitor violence appears to be influenced by the type of interaction and situation, has been shown in previous study [10].

Psychological and verbal violence was extremely high (76.8\% and $80.8 \%$ in the morning shift, $73.6 \%$ and $76.8 \%$ in the evening shift and $40.8 \%$ and $45.6 \%$ in the night shift respectively) a finding compatible with the ones reported from other investigators [12,29,30]. A significant proportion reported incidents of sexual violence a finding also evident in other studies [25,31].

Precipitating factors included violation of visiting hours by the visitor $(88.8 \%)$, long waiting periods (86.4\%), visitors' psychological problems $(83.2 \%)$, and smoking prohibition in the waiting areas $(82.4 \%)$.

Additionally, other causes included denial of patient's admission in the hospital, delays in medical and nursing care provision, denial of patient's dismissal and patient's dissatisfaction with nursing/medical care, a similar finding with previous studies [12].

Younger staff had increased odds of experiencing psychological violence $[2,32]$. These results suggest that there is a clear need for junior staff protection and training in dealing with violence. Personal characteristics like height and weight seemed to predict the risk of experi- 
encing violence. Those with lower height had increased odds of experiencing physical and sexual violence. Combined with the fact that in most cases women have lower somatic characteristics, they may be found in a 'more at risk for violence' situation [20,33].

Our results showed that working in the internal medicine, surgical and anesthesiology, increased the risk of experiencing violence. Working in emergency increased the risk of experiencing sexual violence. These results are consistent with previous studies [6,9,25,34]. In Greece, lack of nursing and medical staff, difficult shifts and intensity of the work required, may increase the tension when working in these wards. In addition, visitors may be frustrated and impatient regarding patient progress. Combined with the fact that they participate in patient care in many ways, interactions with staff may turn to be problematic even violent.

Issues raised by nurses and physicians

Shortage of staff was the most common issue raised by nurses. Combined with a large workload, it was the main reason for interrelationship tension, unmet patients' and relatives' demands and violent episodes [11].

In our study victims were unlike to report the incidents [35]. They tended to keep the problem for themselves or share the experience with a colleague, a similar finding with previous studies $[17,18]$.

It is of note that Greek health care staff has no training in violence de-escalation strategies. Additionally, for many of them, seeking support from colleagues seems to be their only solution $[34,36]$.

Most of the respondents-especially nurses - noted that nursing or medical administration would never come to their aid even if they had reported the incident or expressed fear for consequences from management $[11,13]$. Organizational issues included lack of security policies and measures to protect staff. Nurses and physicians proposed hospital management implementation strategies to prevent and manage violent acts and support staff after the violent incident.

Greek economic crisis seems to have an impact on various health care sectors. It is of note that the total sample believed that there was an increase in violent incidents since the onset of the crisis. As shown in previous study concerning the impact of financial crisis on the Greek health care system, the reduction on hospital budgets and salaries, the staff shortage, the lack of medical supplies and medication in public sector all have a detrimental effect in health care [37].

The serious impact of violence at work is becoming a topical subject in various health care systems. It is generally accepted that studies must focus on prevention programs and safety measures in order for health care staff to feel less vulnerable in the health care sector $[38,39]$. In Greece especially, there is a growing need for systematic evaluation of care provision under the current economic situation.

\section{CONCLUSION}

Violence against health care staff provoked by patient visitor is an underestimated phenomenon in Greek hospitals. In Greece, patients' relatives play a key role in patients' care due to a lack of health care staff. This study provides evidence of the problem and highlights the main participating factors. Working in a safe environment should be a priority $[39,40]$. The implementation of strategies and preventive measures seems imperative for health care staff to feel secure and confident in health care environment [41]. Future research has to investigate in depth of the phenomenon and illustrate possible safety measures and strategies under the current economic deprivation. Researchers in the future, should focus on possible negative changes concerning care provision in the public sector, due to the economic crisis.

\section{LIMITATIONS}

This study represents an initial attempt to identify the problem of violence in health care and to recognize a possible effect of economic crisis amongst other reasons. Further research is needed to determine the factors associated with violence increase and to identify any possible changes, two years (2011-2013) after the beginning of economic crisis in Greece.

Ethical approval was obtained by the ethical committee of general hospital "George Gennimatas" (registration No 17774).

\section{REFERENCES}

[1] Warren, B. (2011) Workplace violence in hospitals: Safe havens no more. Journal of Healthcare Protection Management, 27, 9-17.

[2] Wells, J. and Bowers, L. (2002) How prevalent is violence towards nurses working in general hospitals in the UK? Journal of Advanced Nursing, 39, 230-240. http://dx.doi.org/10.1046/j.1365-2648.2002.02269.x

[3] McKenna, B., Poole, S.J., Smith, N.A., Coverdale, J.H. and Gale, Ch.K. (2003) A survey of threats and violent behavior by patients against registered nurses in their first year of practice. International Journal of Mental Health Nursing, 12, 56-63.

http://dx.doi.org/10.1046/j.1440-0979.2003.00269.x

[4] Chapman, R. and Styles, I. (2006) An epidemic of abuse and violence: Nurse on the front line. Accident and Emergency Nursing, 14, 245-249. http://dx.doi.org/10.1016/j.aaen.2006.08.004

[5] Farrell, G.A., Bobrowski, C.H. and Bobrowski, P. (2006) Scoping workplace aggression in nursing: Findings from an Australian study. Journal of Advanced Nursing, 55, 
778-787. http://dx.doi.org/10.1111/j.1365-2648.2006.03956.x

[6] Gates, D.M., Gillespie, G.L. and Succop, P. (2011) Violence against nurses and its impact on stress and productivity. Nursing Economics, 29, 59-66.

[7] Presley, D. and Robinson, G. (2002) Violence in the emergency department: Nurses contend with prevention in the healthcare arena. Nursing Clinics of North America, 37, 161-169. http://dx.doi.org/10.1016/S0029-6465(03)00095-1

[8] Gacki-Smith, J., Juarez, A.M., Boyett, L., Homeyer, C., Robinson, L. and MacLean, S.L. (2009) Violence against nurses working in US emergence departments. Journal of Nursing Administration, 39, 340-349. http://dx.doi.org/10.1097/NNA.0b013e3181ae97db

[9] Taylor, J.L. and Rew, L. (2011) A systematic review of the literature; workplace violence in the emergency department. Journal of Clinical Nursing, 20, 1072-1085. http://dx.doi.org/10.1111/j.1365-2702.2010.03342.x

[10] Hahn, S., Müller, M., Needham, I., Dassen, T., Kok, G. and Halfens, R.J. (2010) Factors associated with patient and visitor violence experienced by nurses in general hospitals in Switzerland: A cross-sectional survey. Journal of Clinical Nursing, 19, 3535-3546. http://dx.doi.org/10.1111/j.1365-2702.2010.03361.x

[11] Algwaiz, W.M. and Alghanim, S.A. (2012) Violence exposure among health care professionals in Saudi public hospitals. A preliminary investigation. Saudi Medical Journal, 33, 76-82.

[12] Winstanley, S. and Whittington, R. (2004) Aggression towards health care staff in a UK general hospital: Variation among professions and departments. Journal of Clinical Nursing, 13, 3-10. http://dx.doi.org/10.1111/j.1365-2702.2004.00807.x

[13] Carmi-lluz, T., Peleg, R., Freud, T. and Shvartzman, P. (2005) Verbal and physical violence towards hospital and community based physicians in the Negev: An observational study. BMC Health Service Research, 15, 5-54.

[14] Inoue, M., Tsukano, K, Muraoka, M., Kaneko, F. and Okamura, H. (2006) Psychological impact of verbal abuse and violence by patients on nurses working in psychiatric departments. Psychiatry and Clinical Neurosciences, 60, 29-36. http://dx.doi.org/10.1111/j.1440-1819.2006.01457.x

[15] Kamchuchat, Ch., Chongsuvivatwong, V., Oncheunjit, S., Yip, T.W. and Sangthong, R. (2008) Workplace violence directed at nursing staff at a general hospital in Southern Thailand. Journal of Occupational Health, 50, 201-207. http://dx.doi.org/10.1539/joh.O7001

[16] Mirza, N.M., Amjad, A.L., Bhatti, A.B., Mirza, F.T., Shaikh, K,S., Kiani, J., Yusuf, M.M., Khan, M.U., Nazir, M.E., Assad, Q., Humayun, A., Kiani, I.G., Amjad, S.I. and Iman, S.Z. (2011) Violence and abuse faced by junior physicians in the emergency department from patients and their caretakers: A nationwide study from Pakistan. Journal of Emergency Medicine, 42, 727-733.

[17] Fernandes, Ch., Bouthillette, F., Rabound, J.M., Bullock, L., Moore, C.F., Christenson, J.M., Grafstein, E., Rae, S., Ouellet, L., Gillrie, C. and Way, M. (1999) Violence in the emergency department: A survey of health care workers. Canadian Medical Association Journal, 161, 124-129.

[18] Duncan, S.M., Hyndman, K., Estabrooks, C.A., Hasketh, K., Humphrey, C.K., Wong, J.S., Acorn, S. and Giovannetti, P. (2001) Nurses; experience of violence in Alberta and British Columbia hospitals. Canadian Journal of Nursing Research, 32, 57-78.

[19] Camerino, D., Estryn-Behar, M., Conway, P.M., Van Der Heijden, B.I.J.M. and Hasselhorn, H.M. (2008) Workrelated factors and violence among nursing staff in the European NEXT study: A longitudinal cohort study. International Journal of Nursing Studies, 45, 35-50. http://dx.doi.org/10.1016/j.ijnurstu.2007.01.013

[20] Pich, J., Hazelton, M., Sundin, D. and Kable, A. (2011) Patient-related violence at triage: A qualitative descriptive study. International Emergency Nursing, 19, 12-19. http://dx.doi.org/10.1016/j.ienj.2009.11.007

[21] Arnetz, J.E. and Arnetz, B.B. (2001) Violence towards health care staff and possible effects on the quality of patient care. Social Science \& Medicine, 52, 417-427. http://dx.doi.org/10.1016/S0277-9536(00)00146-5

[22] Carroll, V. (2003) Verbal abuse in the workplace. The American Journal of Nursing, 103, 132. http://dx.doi.org/10.1097/00000446-200303000-00050

[23] Nijman, H., Bowers, L., Oud, N. and Jansen, G. (2005) Psychiatric nurses' experiences with inpatient aggression. Aggressive Behaviour, 31, 217-227. http://dx.doi.org/10.1002/ab.20038

[24] King, L.A. and McInerney, P.A. (2006) Hospital workplace experiences of registered nurses that have contributed to their resignation in the Durban metropolitan area. Curationis, 29, 70-81.

[25] Pai, H.C. and Lee, S. (2011) Risk factors for workplace violence in clinical registered nurses in Taiwan. Journal of Clinical Nursing, 20, 1405-1412. http://dx.doi.org/10.1111/j.1365-2702.2010.03650.x

[26] Bonner, G. and McLaughlin, S. (2007) The psychological impact of aggression on nursing staff. British Journal of Nursing, 16, 810-814.

[27] Mayhew, C. and Chappel, D. (2007) Workplace violence: An overview of patterns of risk and the emotional/stress consequences on targets. International Journal of Law Psychiatry, 30, 327-339. http://dx.doi.org/10.1016/j.ijlp.2007.06.006

[28] Hegney, D., Eley, R., Plank, A., Buikstra, E. and Parker, V. (2006) Workplace violence in Queensland Australia: The results of a comparative study. International Journal of Nursing Practice, 12, 220-231. http://dx.doi.org/10.1111/j.1440-172X.2006.00571.x

[29] Pranjic, N., Males-Bilic, L., Beganlic, A. and Mustajbegovic, J. (2006) Mobbing, stress, and work ability among physicians in Bosnia and Herzegovina: Survey study. Croatian Medical Journal, 47, 750-758.

[30] Yildirim, A. and Yildirim, D. (2007) Mobbing in the workplace by peers and managers: mobbing experienced by nurses working in the healthcare facilities in Turkey and its effect on nurses. Journal of Clinical Nursing, 16, 
1444-1453. http://dx.doi.org/10.1111/j.1365-2702.2006.01814.x

[31] Williams, M.F. (1996) Violence and sexual harassment: Impact on registered nurses in the workplace. American Association of Occupational Health Nursing, 44, 73-77.

[32] Magin, P.J., Adams, J., Sibbritt, D.W., Joy, E. and Ireland, M.C. (2005) Experiences of occupational violence in Australian urban general practice: A cross-sectional study of GPs. Medical Journal of Australia, 183, 352-356.

[33] Abualrub, R.F. and Al-Asmar, A.H. (2011) Physical violence in the workplace among Jordanian hospital nurses. Journal of Transcultural Nursing, 22, 157-165. http://dx.doi.org/10.1177/1043659610395769

[34] Kwok, R.P., Law, Y.K., Li, K.E., NG, Y.C., Cheung, M.H., Fung, V.K., Kwok, K.T., Tong, J.M., Yen, P.F. and Leunvg, W.C. (2006) Prevalence of workplace violence against nurses in Hong Kong. Hong Kong Medical Journal, 12, 6-9.

[35] Lovel, A., Skellern, J. and Mason, T. (2011) Violence and under-reporting:learning disability nursing and the impact of environment, experience and banding. Journal of Clinical Nursing, 20, 3304-3312. http://dx.doi.org/10.1111/j.1365-2702.2011.03875.x

[36] Henderson, A.D. (2003) Nurses and workplace violence: Nurses' experiences of verbal and physical abuse at work.
Canadian Journal of Nursing Leadership, 16, 82-98. http://dx.doi.org/10.12927/cjnl.2003.16263

[37] Ifanti, A.A., Argyriou, A.A., Kalofonou, F.H. and Kalofonos, H.P. (2013) Financial crisis and austerity measures in Greece: Their impact on health promotion policies and public health care. Health Policy. http://dx.doi.org/10.1016/j.healthpol.2013.05.017

[38] Catlette, M. (2005) A descriptive study of the perceptions of workplace violence and safety stratiegies of nurses working in level I trauma centers. Journal of Emergency Nursing, 31, 519-525. http://dx.doi.org/10.1016/j.jen.2005.07.008

[39] Gallant-Roman, M.A. (2008) Strategies and tools to reduce workplace violence. The American Association of Occupational Health Nurses, 56, 449-454.

[40] McPhaul, K.M. and Lipscomb, J.A. (2004) Workplace violence in health care: Recognized but not regulated. Online Journal of Issues in Nursing, 9, 7.

[41] Duxbury, J. (2002) An evaluation of staff and patient views of and strategies employed to manage inpatient aggression and violence on one mental health unit: A pluralistic design. Journal of Psychiatric and Mental Health Nursing, 9, 325-337. http://dx.doi.org/10.1046/j.1365-2850.2002.00497.x 